not only is insufficient practice obtained with them to obtain the best results but they may come into disrepute owing to the high mortality apparently resulting.

\section{ReAsons FOR ShORTCOMINGS}

Such then are, in brief, the shortcomings, real or imagined, of our anaesthetic procedure, but before considering remedies it is necessary to investigate the causes.

These fall into two inain categories, traditional and economic, which affect both institutions and individuals. The force of habit, custom, or tradition is fairly strong in most of us, and we probably find it easier to go on doing things in the same way when a good procedure is established. Further, there may be strong national traditions, as, for example, the use of chloroform in Scotland, which we are told was until recently almost universal; or local ones, as a result of which one method may be taught and used almost to the exclusion of all others. Hospital routine or tradition may be reinforced by the conservatism of theatre sisters and nurses, which though it may appear unimportant, can yet provide an effective opposition or a damaging passive resistance. Surgeons, again, who have operated with ease and success for a number of years are naturally prone to look askance at new methods, which may not give the same ease of access as the accustomed one, and may at first take longer in induction. The tradition of haste and hurry which still overshadows some of our theatres is in part a relic of the old pre-anaesthetic days when speed was essential, and in part the result of present economic conditions.

Hospital finances are not as a rule too secure, and committees and secretaries naturally hesitate to order new and possibly expensive machines which may not show any apparent benefit and may be discarded after a few years with the change of fashions or of medical staff. The latter, again, are not likely to be unanimous in their needs, and this may lead to unnecessary reduplication of apparatus.

As we know, the financial position of the individual anaesthetist is in most cases more precarious even than that of the hospitals, if such a thing is conceivable, and the same considerations as to apparatus apply even more strongly to him. His troubles are complicated by the fact that his private work, from which his living is derived, is carried out in nursing homes scattered over a possibly wide area and quite devoid of equipment, even perhaps without a lift. Obviously, such conditions tend to portability and simplicity or crudity of apparatus, and do not favour gas-oxygen.

Hospital practice, which may form the great bulk of his work, is almost entirely unremunerative, though the extension of the system of paying beds may alter this. Though many hospitals when advertising for anaesthetists insist that these should be specialists and not engaged in general practice, yet the possession of such an appointment does not guarantee any financial return whatever. It is therefore hardly surprising if anaesthetists limit their hospital attendances to their specified operation days, and show little inclination to embark upon extensive researches, while on these days conditions seldom favour new or experimental work.

\section{Remedies Proposed}

If progress is to be achieved it must be through the recognition by all concerned in the work of operative surgery, of the importance of anaesthesia as a subject, and of the fact that its technique is not necessarily perfect and stabilized. The status of our subject must be maintained and improved, and in at least .one respect-that is, the time factor-it must take precedence in the theatre; for whatever anaesthetic procedure is adopted it must be completed before the operative procedure is begun. In another respect there is at times room for improvement, and that is in the standard of asepsis, which must be as rigid as possible where spinal, intravenous or other injections are made.

In teaching hospitals at least some attempt should be made by classification and investigation of records to evaluate the advantages and assess the risks of the various methods. This could well be done in the Surgical Units, where conditions should be more favourable, and where an additional anaesthetic assistant might be appointed.

The position of the arraesthetist as a specialist must bo made secure and his services fully utilized in both "normal" and difficult cases, while the question of remuneration for hospital services needs to be considered.

Perhaps most important of all, the demon of hurry and hustle needs to be finally exorcized, and the tyranny of long lists broken.

\section{INDICATIONS FOR PHRENIC AVULSION IN BRONCHIECTASIS}

BY

\section{W. G. OAKLEY, M.B., M.R.C.P.}

Unilateral diaphragmatic paralysis by interruption of the corresponding phrenic nerve is the most recent of the principal methods of securing, by therapeutic collapse, that combination of rest and compression which plays so large a part in the successful treatment of chronic pulmonary diseases. With this object it may be used alone, or in conjunction with such methods as artificial pneumothorax, multiple intercostal neurectomy, and thoracoplasty.

\section{The Radical Operation}

The operative procedure now generally employed consists of avulsion or exairesis of the phrenic nerve through a small incision above the clavicle, for a distance sufficient to ensure breaking its connexion with the supra-pleural plexus and all accessory fibres. Although usually successful, this method has been known to fail in the production of a permanent paralysis, even after as much as seven inches of nerve have been avulsed.

\section{Partial Operations}

In addition to these permanent methods a number of operations have been devised by which a temporary paralysis may be effected in order to permit of healing of a tuberculous lesion and of a subsequent return of function of the diaphragm. These methods include crushing, freezing, alcohol injection, and section with immediate suture of the nerve, and are generally considered less satisfactory than the permanent operations. In bilateral basal bronchiectasis, however, the crushing operation has been successfully combined with phrenic avulsion in America by Matson in the following way. The phrenic nerve is crushed on the worse side, and the effect of a temporary paralysis on cough and sputum observed. If satisfactory improvement results, then the opposite nerve is crushed or avulsed, and the paralysis is later made permanent.

\section{Complications of Radical Operation}

The complications of the radical operation are more formidable in theory than in practice, and fall into three main groups: (a) those due to failure in technique; $(b)$ those due. to adhesions in the course of the nerve; and (c) reflex disturbances.

In the first group haemorrhage constitutes the most frequent and serious of all complications, and results from injury either to the pericardio-phrenic artery (which accompanies the nerve and venae comites in the same 
sheath) or to the subclavian vein. The former is readily controlled, and never fatal ; the latter is far more serious, and has been responsible for the majority of the very few deaths that have been reported. The vein may be torn as the result of tension on the sling formed by the phrenic and accessory phrenic nerves, which pass respectively behind and in front of the vein ; the accessory nerve, however, almost always breaks first. The rarity of haemorrhage is shown by the fact that in Felix's series of 150 cases treated at Munich it occurred but once, and not at all in 300 cases reported by Welles at Saranac Lake. Air embolism is said to be more common in phrenicotomy than in phrenic avulsion, but can be avoided by prompt and careful arrest of haemorrhage. Section of the vagus has been reported in four patients, all of whom died.

The nature of the complication in the second group depends upon the structure to which the nerve is adherent, and varies from slight haemoptysis (when infiltrated lung tissue is unduly stretched) to cold abscess formation, pneumo- and pyopneumo-thorax, and even to fatal mediastinitis when caseous foci are opened up. The presence of a tuberculous empyema, and of pleural adhesions over the nerve, are considered by Sauerbruch and others as definite contraindications to avulsion.

Reflex disturbances are cardiac and respiratory, and probably owe their origin to interference with the vagus and intercostal nerves. They are usually slight and transient in nature, consisting of tachycardia, alterations in pulse volume, and dyspnoea.

\section{Sequels}

The sequels are insignificant and of short duration, consisting most commonly of pain in the corresponding shoulder, and more rarely of tachycardia, dyspnoea, and digestive upsets, which are as rare on the left side as on the right. In two cases reported by Yates spontaneous pneumothorax occurred on the opposite side, due possibly to the production of some slight contralateral emphysema.

\section{Physiology of the Diaphragm: The Effect of} HEMI-PARALYSIS

Before considering the therapeutic application of phrenic avulsion it is important to review the normal respiratory function of the diaphragm and the physiological effects of paralysis af one or both domes, since on these follow, to some extent, the uses and limitations of this method of treatment. In man one-third of the total air inspired is due to the action of the diaphragm in keeping the lower lobes fully expanded, and the basal collapse which results from its paralysis is brought about by the unopposed action of the abdominal muscles. Phrenic avulsion affects primarily the position, movement, and structure of the corresponding half of the diaphragm, and thereby, secondarily, the thorax and its contents. The paralysis induced is strictly unilateral, and is evidenced by an immediate and progressive rise of the dome, which, in the course of three to six months, undergoes complete atrophy and is converted into a thin parchment-like structure. There are two principal forces acting on the paralysed dome to produce this rise: (a) the upward pressure of the abdominal contents; (b) the intrathoracic pull due to the natural retraction of elastic tissue in the lung, and to the contraction of the abnormal fibrous tissue. The second force may act over a long period, especially in cases of pulmonary tuberculosis, from a case of which Matson obtained the following figures: rise at operation, $3 \mathrm{~cm}$. ; rise one year after operation, $9.5 \mathrm{~cm}$. ; rise two years after operation, $13 \mathrm{~cm}$.

The rise obtained depends on the side affected, the presence and extent of adhesions (especially in the costophrenic angle), and on the consistency of the overlying structure. The upward pressure of the liver on the right, and the interference of the heart on the left, are together held responsible for a difference of about two centimetres between the average figures quoted for the two sides: rise on the right side, 5 to $7 \mathrm{~cm}$. ; rise on the left side, 3 to $5 \mathrm{~cm}$. The presence of fluid or of a resistant fibrous lower lobe may greatly reduce these figures.

When the full expiratory position has been reached, any movements exhibited by the paralysed muscle are usually paradoxical in nature, and best recognized by Bittorf's method of attempted inspiration with closed mouth and nose.

The effect of phrenic avulsion on the thorax is to decrease the capacity of the corresponding lung by onefourth to one-third, or on the right side by four to eight hundred cubic centimetres (Brunner).

Goetze stated that a successful phrenicotomy is as good as a pneumothorax, and this may be true in those cases where a very high rise takes place. This reduction in lung capacity is not sufficient to produce dyspnoea in any but advanced cases of bilateral disease, and, for reasons given below, phrenic avulsion more often relieves than produces this symptom. Even in the few cases of bilateral paralysis reported in man there is the same absence of respiratory embarrassment that was noted by Lemon in experiments on dogs.

The chief intrathoracic structures affected by this sequence of events are the lungs and the heart, the latter being displaced upwards in left-sided paralysis sufficiently to relieve, in some cases, the palpitations and tachycardia which result from the drag of pleural adhesions.

The effects produced on the lung itself are therapeutically by far the most important, and consist of partial compression and relaxation, with the addition of rest, consequent upon the removal of the forces exerted upon it by the contractions of the diaphragm. While the truth of this general statement is accepted, there remains some disagreement about the extent of the lung tissue thus affected, and consequently, from the point of view of localization of the lesion, on the type of case in which phrenic avulsion is most indicated. Some observers limit the effect to the lower lobe, while others claim that the effect on the apex is as great as on the middle and lower lobes, in that the diaphragm exercises an equal pull on any part where there is a counter-pull.

\section{Effect of the Type of Lesion}

These divergent opinions suggest that, in addition to, and probably more important than, localization, there is some intrinsic property of the lesion upon which depends the success of treatment by phrenic avulsion. The capacity for spontaneous retraction and collapse being in theory a lesion's most essential property in this or any other form of collapse therapy, better results should be expected in the proliferative or productive than in the exudative type of pulmonary tuberculosis. Alexander. and others have found in practice that this property is of more importance than the position of the lesion, and that if present in an otherwise suitable case, not only are the results good, but are in some measure proportional to the degree of collapse and compression obtained.

In bronchiectasis, however, this process of spontaneous retraction is so often responsible for the production and progression of the lesion that the results of phrenic avulsion must therefore depend upon its success in actively collapsing and compressing the dilated bronchi. Now it is obvious that active compression in diaphragmatic paralysis is greatest at the base, and, in the presence of dilated bronchi and pulmonary fibrosis in this position, will become increasingly less as the apex is approached. The position and extent of the lesion, therefore, together with the degree of rise of diaphragm obtained, are likely to be the most important factors in the treatment of bronchiectasis by phrenic avulsion. 
Indications for Phrenic Avulsion

Before it is decided whether this supposition is sup. ported by the clinical findings in the cases reported, the general indications for diaphragmatic paralysis in chronic pulmonary disease will be briefly classified. The indications may be considered under the two main headings of tuberculous and non-tuberculous disease.

\section{Tuberculous Disease}

1. Definitely basal lesions; here phrenicotomy has its most consistently successful results in tuberculosis.

2. Unilateral disease in which sanatorium treatment alone is insufficient, and artificial pneumothorax, though indicated, bccause of adhesions or for social reasons, is not possible.

3. In chronic cases where artificial pneumothorax is impossible and thoracoplasty in contraindicated, phrenic avulsion on the worse side may cause great improvement, especially if the lesion is of the proliferative type.

4. Combined with artificial pneumothorax for one or more of the following reasons: (a) basal adhesions; $(b)$ to assist re-expansion; $(c)$ to prolong the interval between refills and lessen the incidence and amount of effusion and mediastinal displacement.

5. As a preliminary to thoracoplasty: (a) to remove, if possible, the need for thoracoplasty; $(b)$ to make thoracoplasty possible by improving the patient's condition; $(c)$ to test the opposite lung; $(d)$ to assist by collapsing the base of the lung, or, in tuberculous empyema, by decreasing the size of the cavity ; $(e)$ to prevent aspiration to the lower lobe.

6. As symptomatic treatment to relieve: (a) cough and vomiting; (b) copious expectoration; $(c)$ haemoptysis ; $(d)$ dyspnoea ; $(e)$ pleural pain ; $(f)$ persistent hiccup ; $(g)$ tachycardia and palpitations resulting from cardiac embarrassment; (h) pyrexia.

\section{Non-tuberculous Disease}

1. Bronchiectasis

2. In unresolved pneumonia as prophylaxis against bronchiectasis.

3. Subacute and chronic pulmonary abscess.

4. Hydatid disease of the lung.

\section{BRONCHIEC'TASIS}

As a therapeutic measure in bronchiectasis phrenic avulsion has received less attention than in tuberculosis, and consequently the literature contains fewer opinions on its uses and limitations. The results obtained in bronchiectasis by this form of treatment, and consequently the conclusions arrived at, agree no better than those reported in connexion with pulmonary tuberculosis, and suggest that the indications for phrenic avulsion in the former disease are not fully realized or understood.

The following series of cases, collected over a period of three years at St. Bartholomew's Hospital, have been followed up and analysed to discover, if possible, the indications and contraindications for phrenic avulsion in bronchiectasis.

Clinical Observations.-Seventeen cases are reported, in all of which the diagnosis of bronchiectasis was based on clinical and $x$-ray findings, lipiodol being used in almost every instance. The original lesions responsible for the bronchiectasis were traced wherever possible, and found to comprise the following conditions: pneumonia, 9 ; "influenza," 1 ; foreign body, 1 ; $x$-ray treatment for carcinoma of breast, 1 ; new growth, 2 ; unknown, 3. The operation was carried out nine times on the left side and eight times on the right, paralysis of the corresponding dome being observed by $x$ ray in every case. The technique employed was that of avulsion of the nerve, or, failing this, of radical excision.
Complications.-Pain in the corresponding shoulder occurred in about half the cases. Section of the thoracic duct occurred once, and was followed by a chylous discharge of short duration. Serious haemorrhage was entirely absent from this series.

Previous Treatment.-In four cases artificial pneumo thorax was attempted, but prevented by adhesions in all but one, in which it was successful in relieving the cough. As soon, however, as the air was absorbed the cough returned, and necessitated a subsequent phrenic avulsion. Creosote baths were unsuccessful in the few cases in which they were tried. Postural drainage was employed before operation in all cases with much sputum

\section{Results in Cases Treated}

The results in the seventeen cases of bronchiectasis may be summarized under three headings: (1) those in which the symptoms were completely relieved ; (2) those in which improvement was being maintained when the patient was last seen ; (3) those in which temporary improvement was followed by relapse.

The first group contains four cases which deserve brief mention.

In Case 1 a phrenic avulsion was performed without success on a man who had a persistent distressing cough with copious foul sputum. Five months later a collar stud was removed from the left lung through a bronchoscope, and a complete cure resulted in a few months. In view of the very advanced cavitation of the left lower lobe, demonstrated by lipiodol $x$ ray, it is reasonable to suppose that the phrenic avulsion, by assisting in the obliteration of the cavities, was in part responsible for the rapid cure.

Case 2, a girl aged 20, with left-sided bronchiectasis following pneumonia in infancy, was treated by paravertebral thoracoplasty in August, 1926, with great success. Five months later the patient still had a cough, "with greatly diminished sputum $(1,200 \mathrm{c} . \mathrm{cm}$. to $60 \mathrm{c} . \mathrm{cm}$. per diem), and a left phrenic avulsion was therefore performed, since which there has been complete relief of symptoms. Here the usual sequence was reversed, but the value of diaphragmatic paralysis as a complement to thoracoplasty is well illustrated.

In Cases 3 and 4 no other treatment contributed to the success of phrenic avulsion. In the former, that of a girl aged 15, the only symptom was cough, which was persistent and dry. Lipiodol $x$ ray showed dilatation of the left lower lobe. Phrenic avulsion was followed by disappearance of the cough, which has not returned.

The last case of so-called "cure" was that of a boy, aged 14, with a history of broncho-pneumonia when 4, followed three years later by two separate large haemoptyses. Vaccine treatment was carried out at a sanatorium for two years, and the boy remained quite well until, at the age of 14, he developed a cough, with much sputum. Lipiodol $x$ ray showed basal bronchiectasis, and phrenic avulsion was performed in June, 1927. There was an immediate decrease in cough and sputum, which fell from over $200 \mathrm{c.cm}$. of muco-pus to about $5 \mathrm{c.cm}$. of clear mucoid secretion daily. Nine months later he was symptom-free, and is now able to swim and play football without cough or shortness of breath. There has been no further haemoptysis.

It is important to observe that in these four cases the lesion was not only basal, but completely confined to the side on which phrenic avulsion was performed, a conbination of characteristics not to be found in any of the cases of improvement now to be considered.

The second group contains seven cases in which there has been lasting improvement in general conditions and weight, in addition to reduction or disappearance of cough or sputum. In six cases the condition of the patient is stationary, while the seventh and most recent of the series has been improving ever since his operation five months ago. Four cases gave a history of pneumonia. 
Summary of Resulls of Seventeen Cases of Bronchiectasis treated at St. Burlholomez's Hospilal by Diaphragnalic l'araly'sis belene'n 1927 and 1930

\begin{tabular}{|c|c|c|c|c|c|c|c|c|c|c|c|c|c|c|c|c|c|}
\hline \multirow[b]{2}{*}{ 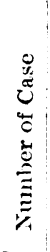 } & \multirow[b]{2}{*}{ 节 } & \multirow[b]{2}{*}{$\stackrel{0}{4}$} & \multirow[b]{2}{*}{ 呇 } & \multirow[b]{2}{*}{ 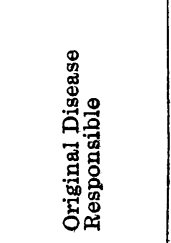 } & \multirow[b]{2}{*}{$\begin{array}{l}\text { Extent of Lesion Indicated by } \\
X \text {-Ray Exannination. } \\
\text { (Lipiodol used in all but Case 8.) }\end{array}$} & \multicolumn{4}{|c|}{ On Admission } & \multicolumn{3}{|c|}{$\begin{array}{l}\text { Lnmediately after } \\
\text { Operation }\end{array}$} & \multirow{2}{*}{ 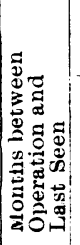 } & \multicolumn{4}{|c|}{$\begin{array}{l}\text { When Last Seen or } \\
\text { Heard of }\end{array}$} \\
\hline & & & & & & 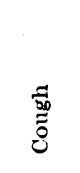 & 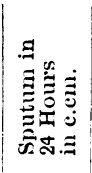 & 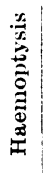 & $\frac{D}{0}$ & 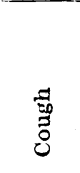 & 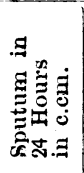 & 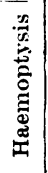 & & 获 & 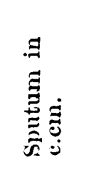 & 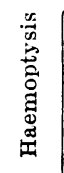 & 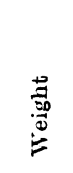 \\
\hline 1 & 8 & 48 & R. & Foreign body & $\begin{array}{l}\text { Cavitation r. lower lobe; collar } \\
\text { stud seen }\end{array}$ & ++ & 400 & - & st. ll). & +++ & 400 & - & $?$ & Nil & $N 1$ & - & st. 11 ?. \\
\hline 2 & $q$ & 20 & IR. & Pneumonia & $\begin{array}{llll}\text { Cavitation } r \text {. base } & \ldots & \ldots & \ldots\end{array}$ & + & $30-60$ & + & 84 & + & $30-60$ & - & 45 & Nil & Nil & - & 810 \\
\hline 3 & $q$ & 15 & L. & Pneumonia & Bronchiectasis l. lower lobe & ++ & Nil & - & $?$ & Nil & Nil & - & 12 & Nil & Nil & - & $?$ \\
\hline 4 & d & 14 & L. & Pneumonia & Bronchiectasis 1. lower lobe & ++ & $25-100$ & + & $?$ & + & Less & - & 40 & Nil & Nil & - & 97 \\
\hline 5 & $q$ & 12 & R. & Pneumonia & Extensive bronchiectasis of all & ++ & Trace & - & 43 & + & Nil & - & 12 & & Nil & - & \\
\hline 6 & q & 56 & L. & $\begin{array}{l}\text { Carcinomá } \\
\text { breast: } x \text { ray }\end{array}$ & $\begin{array}{l}\text { Fibrosis and bronchiectasis of } \\
\text { upper and mid zones of l. lung }\end{array}$ & ++ & Trace & - & 91 & + & $?$ & - & 12 & $\begin{array}{l}\text { lisht } \\
+\end{array}$ & I.S.Q. & - & \\
\hline 7 & $q$ & 40 & L. & Pneumonia & Bronchieitasis of l. lung $\quad \ldots \quad \ldots$ & +++ & $25-50$ & + & 512 & ++ & Less & - & 11 & + & $10-25$ & - & 65 \\
\hline 8 & $\delta$ & 13 & R. & Pneumonia & $\begin{array}{l}\text { Bronchiectasis of both bases, } \\
\text { r. more than 1. }\end{array}$ & +++ & $50-1 \mathrm{co}$ & - & 410 & ++ & $25-50$ & - & 5 & + & $c-50$ & - & \\
\hline 9 & 8 & 13 & R. & $?$ & $\begin{array}{l}\text { Atelectatic lo lower lobe with } \\
\text { bronchiectasis }\end{array}$ & +++ & $100-200$ & + & 312 & ++ & Less & - & 22 & + & Nil & - & 413 \\
\hline 10 & 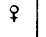 & 34 & L. & $?$ & Bronchiectasis l. Jower lobe $\quad$... & ++ & $50-90$ & + & 810 & ++ & $2 ;-50$ & - & 38 & + & 15 & - & 8 \\
\hline 11 & $\delta$ & 13 & L. & Pneumonia & $\begin{array}{l}\text { Fibrosis and bronchiectasis of both } \\
\text { lobes of } 1 \text {. lung }\end{array}$ & ++ & 25 & - & 64 & ++ & $5-10$ & - & 15 & + & $5-15$ & - & \\
\hline 12 & 8 & 54 & L. & New growth & Solid l. lower lobe? bronchiectatic & $+t$ & 180 & + & 710 & + & I.S.Q. & + & $?$ & ++ & I.S.Q. & + & $?$ \\
\hline 13 & 8 & 46 & R. & New growth & Bronchiectasis of $r$. base $\quad \ldots \quad \ldots$ & +++ & $100-200$ & - & 811 & + & I.S.Q. & - & 22 & ++ & Less & - & 911 \\
\hline 14 & $\delta$ & 26 & R. & "Influenza" & $\begin{array}{l}\text { Broncbiectasis of } x \text {. lung, base and } \\
\text { apex involved }\end{array}$ & ++ & 150 & + & 713 & Nil & Nil & - & 38 & ++ & $150+$ & ++ & 814 \\
\hline 15 & 8 & $?$ & R. & $?$ & Bronchiectasis of r. base $\ldots, \ldots$ & ++ & 1,200 & $?$ & $?$ & Less & 120 & $?$ & $?$ & ++ & 1,200 & $?$ & $?$ \\
\hline 16 & 8 & 25 & L. & $\begin{array}{c}\text { Post-operative } \\
\text { pneumonia }\end{array}$ & $\begin{array}{l}\text { Bronchiectasis of mid zones and } \\
\text { bases of both lungs; left }>\text { right }\end{array}$ & $++t$ & 300 & + & 811 & ++ & $3 \mathrm{co}$ & - & 3 & ++ & I.S.Q. & + & 911 \\
\hline 17 & 3 & 18 & L. & P'neumonia & $\begin{array}{l}\text { Advanced hronchiectasis of l. lower } \\
\text { lobe with fibrosis and ? collapse }\end{array}$ & + & $15-25$ & + & 80 & + & 5 & - & 18 & + & 25 & - & 92 \\
\hline
\end{tabular}

one of $x$-ray treatment following removal of the left breast for carcinoma, and in two no cause could be traced. The maximum daily sputum before operation was $200 \mathrm{c} . \mathrm{cm} .$, and after operation $25 \mathrm{c.cm}$. In two cases sputum has disappeared altogether, in four it has decreased in amount, and in one it has remained the same. In all seven cases cough is still present, but improved, and up to date there has been no recurrence of haemoptysis in the three cases in which it had occurred before operation. In this group the disease in three cases was completely unilateral but very extensive, involving both upper and lower lobes. Two cases showed $x$-ray evidence of involvement of the opposite base, and in the remaining two moist added sounds were persistently audible in the same situation.

The third group contains six cases in which temporary improvement was followed by relapse. The symptoms in two cases were subsequently found to be due to new growth of the lung, which proved fatal shortly after the operation. Quite remarkable improvement followed phrenic avulsion in two cases with much sputum. In one the sputum was reduced from $1,200 \mathrm{c} . \mathrm{cm}$. to $120 \mathrm{c} . \mathrm{cm}$., and thoracoplasty, though indicated on account of the extent of the lesion, was unfortunately refused. In the second case both cough and sputum rapidly disappeared, but recurred after a short interval. Here, again, the lesion involved the whole of one side, retention of secretions causing pain over the upper lobe, which was relieved by postural drainage. The remaining two cases showed a slight but definite improvement, consisting in the one of reduction of cough, and in the other of decrease in sputum. A subsequent thoracoplasty was intended in one case, but had not been performed when the patient was last heard of six months ago. In both these cases not only were there bilateral basal lesions, but the midzones were also involved, and in one there was evidence before operation of collapse of the corresponding base.
Summary of Results

In the seventeen cases of bronchiectasis phrenic avulsion gave the following results:

\begin{tabular}{cccccc} 
& \multicolumn{4}{c}{ Cases. } & Percentage. \\
Complete relief of symptoms & $\ldots$ & $\ldots$ & 4 & $\ldots \ldots$ & 23.5 \\
Lasting improvement ... $\ldots$ & $\ldots$ & $\ldots$ & 7 & $\ldots \ldots$ & 41.0 \\
Temporimy improvement, with relapse & $\ldots$ & $\mathbf{6}$ & $\ldots \ldots$ & $\mathbf{3 5 . 5}$ \\
Conclusions & & & &
\end{tabular}

1. Phrenic avulsion in experienced hands is a safe operation, and the complications are more to be feared in theory than in practice.

2. Only in strictly basal and unilateral cases of bronchiectasis can phrenic avulsion be reasonably expected completely to relieve the symptoms.

3. Improvement is to be expected in unilateral bronchiectasis in which the lesions are confined to the bases and not advanced on the better side.

4. In unilateral bronchiectasis in which the lesion extends into upper or mid-zones, temporary improvement is the rule, but relapse must be expected unless thoraco plasty is performed.

5. In bilateral basal bronchiectasis with lesions in upper or mid-zones, little benefit is to be hoped for from unilateral diaphragmatic paralysis.

6. As a preliminary to thoracoplasty phrenic avulsion should always be performed, but should not be allowed to shelve the larger operation in event of a brilliant but temporary cure.

For permission to record the cases described I an indebted to the physicians and surgeons under whose care they were admitted to hospital, and particularly to Mr. J. E. H. Roberts, who performed the great majority of the operations.

$$
\text { BIBLIOGRAPHY }
$$

Burrell, L. S. T.: Recent Advances in Pulmonary Tuberculosis, 1. 209.

Campbell, A. J.: Quart. Jowrn. Med., 1928,.xxi, 463.

Iavies, H. Jilorriston: British Medical Joumal, 1926, i, 316

Lemon, W. S.: Arch. of Surg., 1927, xiv, 352.

Matson, R. W.: Amer. Rev. of Tuberculosis, 1930, xxii, 1.

Welles, E. S.: Arch. of Surg., 1929 (Part 2), xix, 1169. 